\title{
Importancia del sector industrial en el desarrollo económico: Una revisión al estado del arte
}

\author{
Medardo Palomino \\ Universidad Santiago de Cali
}

\section{Resumen}

El presente artículo busca promover el conocimiento y abrir el debate sobre la pertinencia de la política industrial y la implementación de políticas públicas que tienen el objetivo de dinamizar el crecimiento industrial que conduzca a la economía a un cambio de su estructura productiva y a mayores tasas de crecimiento de largo plazo. Para esto, desde una visión estructuralista y argumentación histórica se ha elaborado un estado del arte que expone la importancia de la industria y de las políticas industriales para el desarrollo de los países. De la revisión de la literatura se puede concluir que el sector industrial manufacturero tiene cualidades importantes para la diversificación productiva y el crecimiento económico de los países, y por lo tanto, debe ser pieza fundamental en la agenda de los gobiernos que buscan promover el desarrollo económico.

Palabras clave: Crecimiento económico, industrialización, diversificación productiva, centro-periferia.

Importance of the industrial sector in economic development: A review of the state of the art

\begin{abstract}
This paper seeks to promote the knowledge and start the debate on the pertinence of the industrial policy and the implementation of public policies whose objective is invigorate the industrial growth that leads to structural economic change and increased long run growth rates. For this, from a structuralist vision and historical rationale a literature review has been elaborated that states the importance of the industry and of industrial policies for development of countries. The literature review concludes that the manufacture sector is important for the production diversification and economic growth of countries, therefore, it should be a key piece in the agenda of governments that want to promote the economic development.
\end{abstract}

Keywords: Economic growth, industrialization, productive diversification, centre-periphery.

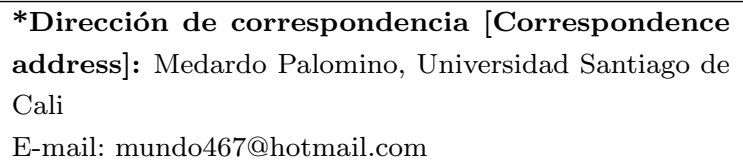




\section{Introducción}

La literatura sobre el crecimiento y el desarrollo económico establece en primera instancia que el proceso de desarrollo de un país está determinado por el cambio en su estructura productiva y en su mayor diversificación. En este orden de ideas, en la visión estructuralista, la diversificación productiva explica el crecimiento, y no al contrario (Ortiz y Uribe, 2012).

En el proceso de crecimiento económico, el sector industrial es piedra angular para la transformación productiva, al desatar las fuerzas propulsoras del desarrollo que permiten dejar atrás actividades rudimentarias para desarrollar actividades complejas. En segundo lugar, el Estado, a través de políticas comerciales y políticas públicas, específicamente política industrial, ha sido necesario a lo largo de la historia para brindar las condiciones que exige el desarrollo económico, lo cual es contrario a la teoría neoclásica que propone reducir al Estado y dejar actuar las fuerzas del mercado dentro de un marco de libre comercio para alcanzar altas tasas de crecimiento y lograr alcanzar el estadio del desarrollo.

Para desarrollar la idea propuesta, el artículo hace una revisión del corpus bibliográfico sobre el tema y fortalece su discurso argumentativo empleando la exploración de los casos históricos del desarrollo económico (argumentación histórica) ${ }^{1}$. El artículo está organizado en cinco secciones; 1) La Importancia del crecimiento industrial: una revisión de la literatura económica. 2) Proceso de desarrollo industrial: una mirada a la historia económica. 3) Características de los países periféricos. 4) Estado e Industrialización: la política industrial. 5) Conclusiones.

Es importante señalar que tradicionalmente en la literatura de la economía del desarrollo se han empleado dos categorías: países subdesarrollados y países desarrollados, o de otra forma análoga, países pobres y países ricos. El concepto de subdesarrollado puede dar la apariencia de que el organismo económico ha quedado atrofiado sin posibilidad de progreso, contrario a esto, Sarmiento (2014) señala: "todos los países están en capacidad de producir los mismos bienes en condiciones similares, siempre que dispongan de la mano de obra preparada, los ingenieros y la organización administrativa" (424). Por lo tanto, se considera en este artículo que las categorías más adecuadas serían las expuestas por Prebisch y Cabañas (1949) y el estructuralismo, a

\footnotetext{
${ }^{1}$ Un ejemplo del empleo de hechos históricos como sustento de la argumentación se encuentra en Ortiz y Vásquez (2007).
}

saber; países periféricos y países del centro.

\section{Importancia del crecimiento in- dustrial: revisión de la literatu- ra económica}

Se puede definir el desarrollo económico como "un proceso mediante el cual la renta nacional real de una economía aumenta durante un largo periodo de tiempo. Y si el ritmo de desarrollo es superior al ritmo de crecimiento de la población, la renta real per cápita aumentará" (Meier y Baldwin, 1964: 512). En esta definición encontramos que tanto desarrollo como crecimiento económico van de la mano, toda vez que para incrementar la riqueza per cápita de la sociedad se debe tener crecimiento económico. En este sentido, desde el enfoque estructuralista del desarrollo económico se encuentran diferenciales de productividad entre sectores (Chenery et al., 1986) y existe fuerte relación entre el sector industrial y el desarrollo económico (Ortiz y Uribe, 2012). Naudé y Szirmai (2012) sostienen que la industrialización es sinónimo de riqueza, desarrollo económico, liderazgo tecnológico, poder político y dominación internacional, de tal modo que tradicionalmente "la industrialización fue correctamente vista como el motor principal del crecimiento y el desarrollo" ${ }^{2}$ (8). En este orden de ideas, la historia evidencia que a partir de la primera revolución industrial, ocurrida en el siglo XVIII, la brecha entre países ricos y países pobres se ha hecho más grande, siendo así dentro de Europa y aquellos países que fueron llamados del Tercer Mundo (Landes, 2015).

Tanto en la literatura nacional como internacional del crecimiento y el desarrollo económico se encuentra una correlación positiva entre la renta de los países y su nivel de industrialización, por tanto, se afirma que para que los países hoy día pobres adquieran mayor nivel de vida, se requiere que sus aparatos productivos basados en la explotación de recursos naturales sufran procesos de transformación que permitan la elaboración de productos manufacturados y se creen dinámicas de desarrollo que deriven en la producción de bienes cada vez más complejos y de mayor productividad. En primera instancia, se puede decir entonces que existe una relación directa entre industrialización y crecimiento económico ${ }^{3}$ (Ortiz y Uribe, 2012).

En el ámbito académico se ha llegado al consenso

\footnotetext{
${ }^{2}$ Traducción del inglés realizada por el autor.

${ }^{3}$ Ortiz y Uribe (2012) encuentra una relación de causalidad entre industrialización y crecimiento en Colombia. No obstante esta relación se puede extender de forma genérica a todos los países desde la teoría del desarrollo estructuralista.
} 
de que los países se benefician de la productividad y el aumento de ella es una característica de la industria, ésta es importante porque permite aumentar la riqueza del país dados sus recursos, y se refleja, en parte, por la caída de los precios de los bienes y en consecuencia la oportunidad de los hogares a un mayor acceso a ellos, por lo tanto, el aumento en el índice de productividad global implica tanto el aumento en el crecimiento económico como el aumento de los salarios reales (Sarmiento, 2002).

Chang (2007) afirma que en repetidas ocasiones la historia ha mostrado que la distinción más importante entre países pobres y ricos, es que los primeros tienen una elevada capacidad de manufactura, donde la productividad es generalmente más alta y donde tiende a crecer a una tasa más acelerada que en la agricultura y los servicios. Sarmiento (2002, 2011, 2014), en la misma línea, postula la superioridad del sector industrial en materia de productividad. Sarmiento (2002) sostiene que un hecho relevante son las cifras de todos los países en donde se observa que la productividad más alta y con mayor crecimiento ocurre en el sector de la industria; la productividad de la industria -medida como la relación producción/fuerza de trabajo empleadapresenta mayor crecimiento que la de la agricultura y la de los servicios, siendo esta última la que menor crecimiento tiene entre los sectores.

Contrario a los servicios, la industria sí presenta un amplio margen para lograr aumentos de productividad, es el sector de mayor potencial de crecimiento y su incidencia es mayor que su participación en el PIB dadas sus externalidades (Sarmiento, 2011). Al ser la productividad media mayor en la industria que en la agricultura, el factor trabajo se desplaza de la primera a la segunda, aumentando de ésta forma la productividad media de la economía. La productividad de la industria tiende al aumento conforme aumenta la producción y se generan dinámicas de desarrollo en cuanto a las externalidades positivas desprendidas por la industria a otros sectores, de tal suerte que el cambio tecnológico y la formación de capital humano en ésta se esparce a los diversos sectores de la economía contribuyendo al aumento de la productividad en su conjunto (Muns, 1972). Se puede entender entonces que los efectos de la industrialización también radican en el impulso que imprime a otros sectores de la economía.

Como ya se hizo mención, en el proceso de desarrollo económico se ha identificado un patrón en el cual la población ocupada en el campo se reduce frente a la población ocupada en la industria (Muns, 1972), sin embargo, ésta a su vez se reduce frente a la población ocupada en el sector servi- $\operatorname{cios}^{4}$, por lo tanto, teniendo en cuenta que el sector de mayor productividad relativa es el secundario, la productividad a lo largo del proceso de desarrollo incrementa para luego reducirse (Sarmiento, $2002)^{5}$. Se puede decir entonces que los incrementos importantes de la renta per cápita de los países hoy día del centro se lo deben al paso de su mano de obra del sector primario al sector secundario, en donde se tiene mayores posibilidades de crecimiento (Chang, 2007, Sarmiento, 2011), y en donde se crean "las actitudes mentales necesarias para que tenga lugar el progreso". (Muns, 1972: 44). No se puede decir lo mismo del sector servicios; Sarmiento (2002) afirma que mientras la actividad industrial permite la acumulación, organización y puesta en práctica del aprendizaje y las ideas, "los servicios son el producto de una sociedad ociosa que busca más esparcimiento y menos esfuerzo propio. Por eso, la productividad de la industria e incluso la de la agricultura crece más que la de los servicios, y la demanda de estos aumenta más que las de aquellos" (179).

La literatura del crecimiento económico se ha desarrollado con base a modelos matemáticos, funcionales, que buscan explicar el incremento del producto. El primer modelo neoclásico fue el de Harrod Domar, el cual proponía la inversión nacional o extranjera en capital como fórmula para salir de la pobreza. Sin embargo, posteriormente, Paul Baran propuso la necesidad de una revolución social en los países periféricos o de lo contrario la inversión en capital productivo sería infructuosa (Hirschman, 1977). Los modelos de Harrod (1939) y Domar (1946) fueron seguido por otro que tomaba en cuenta la tecnología como variable explicativa del crecimiento junto a los factores productivos trabajo y capital, este modelo fue realizado por Solow $(1956)^{6}$, quien consideró al residuo del producto, que no era explicado por ninguno de los dos factores típicos, como el cambio tecnológico (Mazzucato,

\footnotetext{
${ }^{4} \mathrm{Si}$ bien es cierto que el paso de la economía agrícola a la economía industrial es un signo positivo del progreso, el paso de esta última a una economía de servicios no lo es, puesto que este proceso significa un menor crecimiento de la productividad y del producto nacional y, por lo tanto, de los salarios reales (Sarmiento, 2002), una lógica entendida por medio de lo que se ha expuesto hasta el momento en este artículo.

${ }^{5}$ Para Sarmiento (2002), tanto Inglaterra como EEUU se han resignado a perder cuota de participación en la producción industrial y han permitido que sus economías se direccionen hacia los servicios, sin embargo países como Japón, Alemania y los países del sur de Europa de cierta forma crean restricciones al comercio para "evitar el traslado de mano de obra a los servicios o para demorar los procesos" (117)

${ }^{6}$ La función de producción que expresa la idea del modelo de Solow está dada como la siguiente: $Y=A(t) F(K, L)$, donde $Y$ =producción, $A$ =Tecnología, $t=$ tiempo, $K=$ Capital, $L=$ Trabajo, $F$ (denota funcionalidad). En este modelo la tecnología es función del tiempo. Para una visión general de la función de crecimiento ver Mazzucato (2011).
} 
2011). A partir de éste modelo, se empezó a reconocer la importancia de la tecnología como motor del crecimiento, de esta forma, Kaldor (1961), reconoce en su modelo de crecimiento que la productividad del trabajo es explicada por el progreso tecnológico. El modelo de Solow (1956) dictó el camino para elaborar modelos estilizados que endogenizaron la tecnología, que en éste era exógena - dada como una tendencia del tiempo- tal cual como el crecimiento poblacional; de esta forma nació la nueva teoría del crecimiento (Mazzucato, 2011, Ortiz y Uribe, 2012). Por lo tanto, a partir de estos avances intelectuales, la tecnología en los modelos de crecimiento ya no se tomaría como una variable dada, exógena, sino más bien como una función del gasto en I+D y de la formación del capital humano, lo cual da cabida a los rendimientos marginales crecientes a escala, dicho de otra forma, se produce más con los mismos factores productivos (Mazzucato, 2011). En este sentido, la industria cobra gran importancia, autores como Sarmiento $(2011,2014)$ y Ortiz y Uribe (2012) han señalado que el sector industrial ostenta la mayor capacidad para absorber la investigación tecnológica y conducirla a la producción de nuevos bienes.

Lo señalado anteriormente sobre la divergencia de productividades entre sectores se produce en virtud de la gran capacidad relativa de la industria en la absorción de herramientas mecánicas o máquinas, o dicho en otras palabras, se emplea más equipo por persona en la industria que en la agricultura, lo que permite transformar actividades artesanales en factorías racionalizadas que incrementan la productividad del obrero medio. Por el contrario, históricamente el campo ha presentado ciertas restricciones para el empleo de ciertos bienes de capital lo cual afecta negativamente su productividad (Muns, 1972).

La ventaja del sector industrial radica también en su capacidad de expansión a través del comercio internacional (Sarmiento, 2011, 2014) mientras que los servicios se encuentran confinados al mercado interno y por tanto existe una relación directa entre la exportación de bienes manufacturados y el crecimiento económico (Sarmiento, 2011). En éste respecto, la industria es superior a la agricultura en cuanto a que los bienes del sector primario, si bien se pueden colocar en el mercado externo, su inelasticidad, connatural a estos bienes, reduce su potencial de crecimiento vía demanda ${ }^{7}$. El sector que más se asemeja al industrial es el de la cons-

\footnotetext{
${ }^{7}$ Los productos agrícolas son muy inelásticos en cuanto al ingreso como a los precios, sin embargo los bienes manufacturados tienden a ser más elásticos al ingreso y un poco menos a los precios. Sin embargo, los aumentos constantes de la productividad crecen por encima de la demanda y conducen a la caída de los precios de los bienes. No obstante, esta caída de precios es mayor en la agricultura que en la industria (Sarmiento, 2002).
}

trucción, pero su demanda no es permanente y su productividad es menor.

Aunque la exportación de bienes manufacturados se ha constituido en un patrón de las economías de los países del centro, éstos han tendido a producir la rama más compleja de dichos productos: bienes de capital. En un estudio que se propuso identificar la relevancia relativa tanto del sector industrial de bienes de consumo como de bienes de capital, empleando un cociente Bien de Consumo/Bien de Capital, se encontró que progresivamente a través de los años éste cociente tendió a reducirse (el sector de bienes de capital era mayor al sector de bienes de consumo valorado en producción neta), se sugiere entonces que los países más desarrollados, en gran parte, se convirtieron gradualmente en exportadores de bienes de capital y los países periféricos en importadores de los mismos (Hoffmann, W. G. como se cita en Dobb, 1982: 90). Esto tiene sentido con lo postulado por Ortiz y Vásquez (2007), quienes afirman que la última etapa del cambio estructural es la producción de bienes de capital y equipos de alta tecnología.

Para Dobb (1982), la producción manufacturera de bienes de capital -maquinaria y materiales de construcción- es de gran importancia para el crecimiento de largo plazo y por tanto, siendo la producción de estos bienes el "factor limitativo" del crecimiento de los países con baja dotación de capital y baja renta relativa, las inversiones se deben direccionar hacia las ramas de la producción de bienes de capital para lograr su expansión y poder "construir y equipar a las nuevas fábricas, altos hornos y plantas de energía. De este modo, la construcción de máquinas-herramientas para construir más máquinas-herramientas, será un factor de inducción sobre el desarrollo superior a las industrias productoras de bienes de consumo" (128).

Por su parte, Ortiz (2008) citado por Ortiz y Uribe (2012), le otorga gran importancia a la producción de bienes de capital en el desarrollo de un modelo de crecimiento económico bisectorial suponiendo un "mayor potencial de aprendizaje" en el sector productor de bienes de capital que en el sector de bienes de consumo. Suponiendo a su vez, el aprendizaje como un bien público, el autor encuentra entonces una correlación positiva entre industrialización y crecimiento económico: conforme aumenta el nivel de industrialización, aumenta el aprendizaje que impulsa la productividad industrial y en tal virtud la producción total se acelera.

Sarmiento (2014) expone el proceso dinámico de crecimiento y diversificación industrial afirmando que en la industria, la producción acumulada ${ }^{8}$ de-

\footnotetext{
${ }^{8}$ En Sarmiento (2011) se amplía la idea de la producción
} 
riva en aumentos de la productividad, aumentos los cuales están sujetos al principio de los rendimientos decrecientes, agotándose a una tasa mayor en los sectores de menor complejidad que en aquellos donde la complejidad es mayor. El desarrollo industrial permite entonces que la mano de obra se movilice de los sectores de productividad agotada hacia sectores de alta complejidad relativa, de tal suerte que el sector secundario de la economía revela un "aumento escalonado de la productividad con altibajos" (413). Es de esta forma que los países sufren cambios en sus estructuras productivas pasando de la oferta de bienes rudimentarios a la oferta de bienes complejos ${ }^{9}$; suben por la escalera tecnológica.

La importancia medular del sector industrial en el desarrollo económico radica en que su actividad induce a procesos de aprendizaje en el oficio. La productividad en las actividades de bienes manufacturados aumenta conforme aumenta la producción acumulada (aprendizaje), no obstante, en virtud del agotamiento del aprendizaje se presentan rendimientos decrecientes, lo que implica que la productividad es baja al inicio y crece a tasas decrecientes que tienden a cero (Sarmiento, 2011).

Dado que la industria manufacturera tiene un alto componente tecnológico, el crecimiento y diversificación de su actividad incluye un tipo de aprendizaje en la práctica, el cual es tecnológico, de manera que la diversificación productiva - de la actividad manufacturera - conduce a la economía al empleo y acumulación del conocimiento en términos de ciencia y tecnología ${ }^{10}, \mathrm{y}$, además, permite a la economía mantener autonomía tecnológica ${ }^{11}$ (Ortiz

acumulada como una variable proxi del aprendizaje en el oficio. Esta idea va de la mano con la ley Verdoorn-kaldor "Según la cual los aumentos de producción inducen aumentos de productividad" (Cimoli y Porcile, 2015: 234)

${ }^{9}$ Este proceso es análogo al anteriormente descrito entre sectores, en los cuales el diferencial de productividad induce al desplazamiento del factor trabajo del sector primario al secundario y de éste, al terciario. De igual forma, el desplazamiento estimulado por el diferencial de productividad ocurre dentro del mismo sector industrial. Se aclara que para Sarmiento (2011) la demanda de los servicios crece a tasas mayores a la de los demás sectores y de tal manera que su productividad no encuentra restricciones como si lo encuentra la industria vía demanda insuficiente. El problema de la productividad en la industria termina siendo de demanda y no de capacidad.

${ }^{10}$ Se considera importante en este punto hacer una salvedad expuesta por Ortiz y Uribe (2012) sobre el impacto de la industria en el crecimiento y desarrollo económico; aunque las actividades del sector manufacturero tienen una "mayor composición tecnológica...-no se excluye, por tanto, que otras actividades intensivas en tecnología también puedan liderar el crecimiento económico" (19)

${ }^{11} \mathrm{El}$ concepto de autonomía tecnológica se puede medir mediante el nivel de producción de maquinaria y equipo, a mayor producción de estos bienes el país presenta mayor independencia tecnológica (Ortiz y Uribe, 2012), por el contrario, a mayor importación de estos bienes, mayor dependencia tecnológica (Ortiz y Vásquez, 2007). y Uribe, 2012: 19). Para Ortiz y Vásquez (2007), la dependencia tecnológica impide la acumulación del aprendizaje en la práctica, y por tanto, la acumulación de capital humano; de esta manera induce a la economía a tasas de crecimiento inferiores a las que tendría si acumulase conocimiento tecnológico. Dicho de otra forma, es el aprendizaje en la práctica el que genera rendimientos crecientes a escala en la función de producción y por tanto es motor del crecimiento económico; lo que explica el por qué ciertas empresas o países han superado persistentemente a otros a lo largo del tiempo (Mazzucato, $2011)^{12}$.

Ortiz y Vásquez (2007) atribuyen el gran potencial de aprendizaje de la industria a su relativa independencia de factores naturales y su alta dependencia del conocimiento y la ingeniería; tanto para estos autores como para Sarmiento (2014), es el sector más intensivo en el empleo de la ciencia y la tecnología.

Aparte de la productividad, la alta absorción de la ciencia y la tecnología y el incremento del aprendizaje en la práctica, la industria cuenta con la ventaja de los eslabonamientos productivos, también conocidos por Hirschman (1977) como "enlaces", quien los definió como aquellas fuerzas que inducen a la inversión y también como variable que determina, junto con el ingreso y la demanda, la toma de decisiones empresariales tanto en el sector público como en el privado. Para este autor los enlaces pueden ser de dos tipos: enlaces hacia adelante y enlaces hacia atrás. "Los enlaces hacia atrás conducen a nuevas inversiones en instalaciones proveedoras de insumos y los enlaces hacia adelante conducen a nuevas inversiones en instalaciones usuarias del producto" (1357). La industria tiene grandes enlaces hacia adelante y hacia atrás, estos últimos constituidos por la demanda de bienes intermedios o insumos, además de mantener interrelaciones con los demás sectores de manera que su crecimiento arrastra a todo el sistema económico, que, a la vez, lo impulsa generando un circulo virtuoso en la economía. Este efecto arrastre de la industria se debe también a su mayor componente tecnológico, por tanto, la diversificación de las actividades intensivas en tecnología promueven un mayor uso de la ciencia y la tecnología que repercute en el mayor aprendizaje en la práctica, lo cual aumenta directa o indirectamente la productividad del tejido empresarial en su conjunto, y de ahí, el gran valor estratégico de la industria en el desarrollo económico; ésta permite tener autonomía tecnológica y mayor

\footnotetext{
${ }^{12} \mathrm{El}$ caso soviético ilustra muy bien lo anterior; las autoridades políticas y económicas pusieron gran énfasis en la producción de maquinaria y equipo como forma de lograr ?la independencia económica del Estado soviético? (Javin, 1975: 17).
} 
crecimiento económico (Ortiz y Uribe, 2012).

Por su parte Chang (2007) afirma que las empresas manufactureras son la fuente más importante de demanda de los servicios de alta productividad y en tal virtud, estos últimos no se desarrollarían a falta de un fuerte sector manufacturero. En el mismo sentido, Sarmiento (2014) expresa que "no hay sector de la economía que no le suministre insumos a la industria. De allí la estrecha relación entre el conjunto del sector y sus componentes, o si se quiere, la reducida dispersión entre los sectores industriales" (423).

Dobb (1982) propone que la dinamización de las exportaciones producida por la industrialización, impulsa al mercado interno y cuando éste se diversifica se incrementan las posibilidades de capturar mercados externos y de sustituir importaciones, de tal suerte que el desarrollo industrial va acompañado de superávits en cuenta corriente. Distinto pasa con otros sectores, como el minero, dada su alta productividad relativa, su crecimiento produce un efecto sobre el abaratamiento de las importaciones mucho mayor al de la industria y por tanto su expansión provoca la revaluación que resta competitividad al producto nacional en su conjunto (Sarmiento, 2014).

Se puede afirmar partiendo de lo anteriormente reseñado que las economías que direccionan sus esfuerzos a configurar una estructura productiva con base a la industria manufacturera y tienden a desarrollar actividades complejas, cuentan con una mayor ventaja en el mercado exterior frente a las economías que no lo hacen, toda vez que las actividades que componen el sector secundario emplean "técnicas diferentes y resultan en grandes diferenciales de productividad en el capital y el trabajo", contrario a los bienes rudimentarios, los cuales son sobre-ofrecidos (Sarmiento, 2002: 127).

\section{La industria y sus limitantes: incumplimiento del paradigma ortodoxo}

La industria puede encontrar algunas restricciones en su proceso de crecimiento. Si bien este sector junto a la agricultura presentan las mayores productividades, también son los sectores de mayor limitación de demanda ${ }^{13}$, lo cual provoca un estan-

\footnotetext{
${ }^{13}$ Según la Ley de Engel ?la demanda de alimentos es inelástica con respecto al ingreso? (Ortiz y Uribe, 2012: 45). De la misma forma, se entiende, la situación de la industria es igual al de la agricultura en materia de elasticidad de la demanda.
}

camiento de la oferta de bienes transables ${ }^{14}$. Por tal motivo, Sarmiento (2011) claramente expresa que el incremento de la participación de la industria en el PIB se correlaciona positivamente con el crecimiento del sistema económico siempre y cuando, claro está, no se encuentren limitantes en el mercado externo y la industria no se vea relegada al mercado interno, de lo contrario perdería su capacidad de expansión y arrastre del sistema económico. Los limitantes de demanda interna se solucionan buscando la demanda infinita que ofrece el mercado externo, de no ser así el sector industrial queda confinado, como el sector servicios, al mercado interno ${ }^{15}$.

Los bienes industriales se enfrentan a una demanda inelástica, lo que implica que aumentos de la productividad dan como resultado la perdida de beneficio de los productores en virtud de la caída más que proporcional de los precios de los bienes, de tal suerte que la expansión del sector industrial solo es el resultado de una ampliación de las exportaciones, la sustitución de importaciones y la producción de bienes de capital (Sarmiento, 2014). Esta última idea, sobre la producción de bienes de capital, va en dirección a lo señalado por Dobb (1982) y citado en la sección anterior. En este sentido, Stiglitz (2014) reseña el caso de los EEUU el cual a partir de la segunda guerra mundial experimentó grandes cambios tecnológicos y contó con un incremento importante de la productividad en el sector industrial, pero se enfrentó a una insuficiente demanda, lo que provocó la destrucción de millones de empleos en el sector manufacturero, algo que se agravó con el advenimiento de nuevos países que entraron en la carrera industrializadora y le restaron cuota de participación a las manufacturas estadounidenses en el mercado mundial.

Al enfrentarse la industria a una demanda insuficiente se invalidan dos grandes cimientos del pensamiento neoclásico; la llamada ley de Say y la teoría de las ventajas comparativas. Dada su elasticidad ingreso y precio de la demanda menor a la unidad y la complementariedad de la industria con los servicios, aumentos de la productividad provocan caída

\footnotetext{
${ }^{14}$ Otra restricción que puede tener el proceso de desarrollo industrial es expuesto claramente por Hirschman (como se sita en Ortiz y Uribe, 2012) se encuentra en la clase empresarial en ya establecida; "a menudo, el industrial que hasta ahora ha trabajado con materiales importados estará en contra del establecimiento de industrias nacionales que los produzc".

${ }^{15}$ En Sarmiento (2011) se muestra un ejemplo ilustrativo: "Supongamos que la productividad de la industria crece $5 \%$ y la de servicios $1 \%$. Si la participación de los servicios es $75 \%$, el empleo crece $1 \%$ y los dos sectores crecen al mismo ritmo, el producto crecerá $3 \%$. Si la producción industrial se orienta hacia las exportaciones y crece $6 \%$, los servicios crecerán $2 \%$ y el producto más de $3 \%$. La productividad total del trabajo aumenta. Con la misma mano de obra se produce más" (181)
} 
en la rentabilidad, lo cual evidencia que la oferta no crea su propia demanda, como lo propone la ley de Say, ni existe demanda infinita, como lo supone la teoría de las ventajas comparativas (Sarmiento, 2011). Para Sarmiento (2014), esta última teoría es falsa y no explica la realidad del comercio, en gran parte, porque supone una demanda infinita de los bienes de ventaja comparativa. Tampoco "es cierto que el intercambio dé lugar a más producción e ingresos que la elaboración interna de bienes transables de mayor productividad absoluta. Los países tienen que producir otros bienes - distintos a los de ventaja comparativa - para emplear los factores disponibles, con el fin de equilibrar la balanza de pagos y aumentar la producción" (423). De esta forma se controvierte a la teoría hegemónica del comercio internacional.

\section{Proceso de desarrollo indus- trial: una mirada a la historia económica}

El primer país en dar el salto o en llevar a cabo el despegue fue Inglaterra. Barre (1968) afirma que este país atravesó por una "revolución agrícola", consistente en una serie de cambios en las zonas rurales, que constituyeron uno de los factores que sentó las condiciones para que ocurriese posteriormente la revolución industrial; la revolución agrícola fue caracterizada por un cambio en la mentalidad, explicada en parte por el crecimiento de las ciudades y la mayor demanda de bienes alimenticios, lo cual sirvió de estímulo a la producción. Por otro lado, hubo un aumento de la productividad derivada de mejoras en las técnicas de producción tanto en los cultivos como en el ganado. El resultado final de la revolución agrícola fue el aumento de la acumulación que posteriormente se tradujo en financiación de la industria (Barre, 1968).

De acuerdo con Marx (1867) este proceso de acumulación originario no fue idílico, todo lo contrario, estuvo mediado por la violencia y la expropiación a masas de hombres de los medios de producción. Mijailov (2016) expresa que esta acumulación inicial de capital violenta ocurrió empleando el poder del Estado para despojar a parte de los propietarios de sus tierras y convertirlos en mano de obra para la incipiente industria, la cual no tenía la capacidad suficiente para absorber toda la oferta de trabajo y por lo tanto, creció el desempleo y la indigencia en Inglaterra. Como resultado de lo anterior se acumulaban grandes riquezas a la par que crecía la población en las grandes urbes, lo que se traducía en una mayor demanda que no podía ser abastecida empleando técnicas rudimentarias en la producción; "se precisaba de las máquinas; éstas debían aparecer, y fueron creadas"; no es casualidad que el germen de la revolución industrial estuvo en el rubro de los tejidos, perteneciente a la industria productora de bienes de consumo y mercado de alta demanda (36).

Los procesos de industrialización tienen impactos disimiles sobre la productividad en los distintos países, siendo gradual y más lento en EEUU y Europa que en los países asiáticos, los cuales lograron en cuarenta años lo que los dos primeros hicieron en dos siglos, no obstante, en el caso de América Latina, su avance en los últimos cien años ocurrió de forma más acelerada que EEUU y Europa y menos que los países asiáticos (Sarmiento, 2011). En este sentido, cabe señalar un caso particular, el de la Unión Soviética, caracterizado por tener un vertiginoso desarrollo industrial y crecimiento de la producción total a base de grandes sacrificios en el consumo presente ${ }^{16}$ (Hunt, 1959) y bajo condiciones autárquicas sin acceder al capital extranjero, a través de los famosos planes quinquenales implementados a partir de 1928 (Barre, 1968).

La divergencia en los procesos de industrialización indica la existencia de múltiples formas de desarrollar la industria; los países toman caminos diversos para su desarrollo industrial dependiendo de las condiciones iniciales y del momento en el que entran a la carrera global por la industrialización, debido que los conocimientos científicos y tecnológicos están en constante cambio (Naudé y Szirmai, 2012).

Teóricamente un país puede pasar de una economía agrícola productora de materias primas y de bienes alimenticios a una economía moderna productora de artículos manufacturados y seguir una senda que lo conduzca a la manufactura de bienes de capital y bienes sofisticados de consumo, a través de dos vías, conocidas por Dobb (1982) como la industrialización tradicional y la forma soviética. Esta primera forma de industrialización consiste en la producción de bienes agrícolas, no manufacturados, para posteriormente transformar aquellos bienes agrícolas en bienes de mayor complejidad, dinamizando la industria liviana productora de bienes de consumo final dirigida a los hogares, y luego mucho más tarde, invertir en la industria pesada que se caracteriza por métodos mecanizados. La otra forma, también llamada "orden soviético de desarrollo", mucha más ambiciosa y rápida, consiste en un cambio radical de la estructura productiva; la

\footnotetext{
${ }^{16}$ Hunt (1959) se refiere al proceso de formación de capital en los primeros años de la Unión Soviética como el ?más grande y acelerado esfuerzo económico conocido de la historia? (245).
} 
economía de un país agrícola productor de bienes alimenticios se transforma rápidamente en una economía de alto crecimiento con industria pesada de bienes de hierro y acero $^{17}$, en otras palabras, se pasa de la fase productora de bienes agrícolas a la fase productora de bienes de capital complejos. Tal como sucedió en la URSS bajo condiciones de autarquía (Dobb, 1948; Javin, 1975), lo cual, según Rosenstein-Rodan (1943), representa sacrificios innecesarios para la población y la reducción de la división internacional del trabajo con su consecuente disminución de la riqueza mundial.

De forma análoga, Muns (1972) habla de dos vías de desarrollo, la "industrialización espontanea" y "la industrialización forzada". La primera se identifica por la poca o nula participación del Estado en el proceso de desarrollo, mientras que la segunda se encuentra fuertemente promovida y planificada por éste. La vía espontánea, requiere de la creación de condiciones objetivas en lo concerniente a lo institucional, económico y social, y una vez establecidas dichas condiciones, el proceso de industrialización se lleva a cabo de forma espontánea a través de las decisiones de los agentes económicos privados, proceso en el cual la productividad y la demanda son los dos motores principales que le imprimen "ritmo" a la industrialización (Muns, 1972: 48-49). Sobre el desarrollo industrial bajo el modo espontaneo de crecimiento de los países occidentales se puede decir que "han sido crecimientos complejos y lentos, en todo caso de siglos: evoluciones prolongadas han provocado las necesarias transformaciones económicas, sociales e institucionales" (Barre, 1968: 71).

Para los economistas soviético e indio Feldman y Mahalanobis respectivamente (como se cita en Ray, 1998), la industria pesada es el motor del crecimiento y el desarrollo económico dado que ésta tira de las demás industrias. En consecuencia, las inversiones tendrían que ser direccionadas, como lo indica el "orden soviético de desarrollo" señalado por Dobb (1982), hacia la producción de bienes de capital en lugar de bienes de consumo. Se puede entender también, tomando en cuenta las dos vías del desarrollo industrial de Dobb (1982) y de Muns (1972), que los países priorizarán ciertas industrias dependiendo del grado de intervención del Estado

\footnotetext{
${ }^{17} \mathrm{El}$ caso soviético es ilustrativo; dado que a partir de 1917 se instauró un proceso de transformación socialista y el país atravesaba por una serie de cambios radicales en su organización económica, política y social, el país se vio obligado a priorizar ciertas ramas de la producción que le permitieran tener independencia tecnológica y hacerse de material de guerra para defenderse de un entorno capitalista que le era hostil. En consecuencia, La industrialización debía ser rápida y con ella vendría la autonomía tecnológica (Javin, 1975). Ver Ortiz y Uribe (2012), para conocer una exposición clara de la importancia de la autonomía tecnológica y su relación con la industrialización en el desarrollo económico.
}

en la economía y de las preferencias y posibilida$\operatorname{des}^{18}$ de la clase política referente a la velocidad de la industrialización.

Además de la velocidad y la manera de llevar a cabo la industrialización, existen dos categorías de países en cuanto a sus procesos de desarrollo; países de la industrialización temprana y países de la industrialización tardía (Sarmiento, 2011; Ortiz y Uribe, 2012; Naudé y Szirmai, 2012). Inglaterra, Bélgica, Suecia, Francia y Estados Unidos, son casos de la industrialización temprana, mientras que los casos de industrialización tardía son los de Alemania, Rusia y Japón (Naudé y Szirmai, 2012). Ortiz y Uribe (2012), añade a esta última categoría a Yugoslavia, Corea del Sur, Taiwan, Indonesia, Singapur, Hong-Kong, Brasil, Israel, China y la India.

Surge la pregunta: ¿Cómo se dieron estos procesos de desarrollo industrial? Naudé y Szirmai (2012), citando los trabajos de Crafts, Bergier, Pollard y Von Tunzelmann, describen los diversos caminos de industrialización tomados por lo países de la industrialización temprana. Inglaterra fue el primer país en industrializarse y en convertirse en el líder en producción tecnológica, y lo siguieron países de Europa como Bélgica, Suecia y Francia; en el caso belga, durante el periodo 1815-1850, se siguió el mismo camino hacia la industrialización beneficiándose de los recursos naturales al sur de su territorio, explotando minas de carbón, dinamizando la ingeniería y el sector textil. Por el contrario, Suecia al tener escasez relativa de recursos naturales, sin carbón, hierro, o recursos minerales, y además, un limitado mercado interno, sus esfuerzos se concentraron en bienes de tecnología avanzada como los relojes y las sedas finas. Por su parte, Francia se dedicó a la producción de bienes de alta calidad y bienes de lujo, explotando su factor trabajo. Para el caso de EEUU, a pesar de exportar bienes primarios y contar con bastos recursos naturales, como la tierra, presentó relativa escasez del factor trabajo, en virtud de que los trabajadores podían cultivar su propia parcela (Kalmanovitz, 2011) y por tanto se estimuló el empleo de técnicas de producción altamente intensivas en capital, lo cual permitió cambiar la matriz productiva del país, alcanzando aceleradamente grandes productividades (Naudé y Szirmai, 2012). Los bienes de capital que no eran empleados en Inglaterra

\footnotetext{
${ }^{18}$ Se habla de posibilidades porque se puede dar el caso de que la burguesía industrial, ya formada en los primeros años del proceso de capitalización, se oponga a los cambios en la matriz productiva toda vez que defienden sus intereses económicos representados en el status quo; temen que sus beneficios disminuyan si se fomenta la creación de nuevas industrias y se reemplaza producción extranjera por nacional, se habla entonces, como lo expresara Acevedo, Quirós y Restrepo (como se cita en Ortiz y Uribe, 2012) de una burguesía industrial anti-industrialista.
} 
por sus relativos salarios bajos eran empleados por EEUU (Kalmanovitz, 2011). Aparicio (2013) toma el crecimiento demográfico como factor positivo en el desarrollo de los Estados Unidos; la gran explosión demográfica de 1850-1920 (la población creció de 23,2 a 105,7 millones) se constituyó en un gran mercado aprovechado por los industriales que contaron con vías férreas para movilizar las mercancías y también significó trabajadores para las fábricas.

Por otro lado, Japón es un ejemplo de desarrollo cerrado a finales del siglo XIX, tratándose de una isla relativamente pequeña es un ejemplo interesante. Dado el temor de su clase dirigente a depender del crédito extranjero y perder su independencia financiera, se optó por financiar su desarrollo con recursos internos y por tal motivo la afluencia del capital extranjero al Japón no fue muy importante para el periodo 1868-1895. Su desarrollo tuvo gran participación Estatal, dedicada "a favorecer la industria y a favorecer a la empresa privada" (Barre, 1968: 108). Es un ejemplo entonces de sinergia Estadomercado. Según Chang y Green (como se cita en Valencia, 2016), la inversión extranjera en Japón antes de 1963 se limitaba al $49 \%$ en algunas industrias, sin embargo, se prohibía al capital extranjero tomar posesión de las "industrias vitales" del país, estas solo podían ser de capital nipón; al capital se le impusieron restricciones a tal punto que incluso en 1969 "no se permitía la inversión extranjera en industrias estratégicas como la de automóviles y la petroquímica" (Valencia, 2016. p.56). Según este autor, Inglaterra, Francia y Alemania, después de la segunda guerra mundial, adoptaron controles a la IED, control de cambio y el Estado tuvo participación en sectores importantes, a la vez que se le exigía al capital "requisitos de desempeño" (55), tal cual como ocurrió en el caso de Corea del Sur (Ortiz y Uribe, 2012).

Los instrumentos del Japón para financiar su desarrollo eran los prestamos interiores (deuda interna), emisiones de papel moneda (de 1872 a 1881 el gobierno emitió 118.9 millones de yenes, obteniendo un alza nominal de precios del 10\%), y el aparato tributario, siendo el impuesto más importante el impuesto a la tierra, establecido como impuesto en dinero en 1873, basado en el valor de la tierra y según la importancia de la cosecha; hasta 1882 aportó el $80 \%$ de los ingresos fiscales (Barre, 1968: 110). El impuesto favoreció la explotación agrícola en cuanto a que los pequeños productores, menos eficientes, salían del mercado al no poder pagar el impuesto a la tierra, dicho de otra forma, no justificaban así su derecho a poseer tierra. Como consecuencia se produjo un éxodo rural necesario para desarrollar la industria además del aumento de la productividad agrícola que contrarrestó las presiones inflacionarias producto de las inversiones industriales, y por otra parte, evitó un problema en la balanza de pagos al prescindir de las importaciones de artículos alimenticios (Barre, 1968.). Se originó entonces en Japón un proceso parecido al de Inglaterra, en donde los habitantes del campo migran, ya se voluntariamente o por la fuerza, hacia las grandes urbes para convertirse en mano de obra industrial.

Los cambios en el sector primario de la economía no solo se limitan a Inglaterra y al Japón, asimismo ocurrió en la Unión Soviética, en donde se colectivizó la tierra con el propósito de aumentar la productividad en el campo a través de las cooperativas Koljós (Barre, 1968), lo que es síntoma de la necesidad de los países de liberar trabajo para la industria. Corea del Sur, Taiwán, Singapur, Indonesia y China son otros ejemplos (Ortiz y Uribe, 2012). También el caso de Israel es bastante ilustrativo, siendo un país con poca tierra disponible para solventar su problema alimentario, puso en orden su agricultura antes de iniciar su desarrollo industrial bajo una fuerte planificación y dirección estatal (Tzur, 1961).

Los países asiáticos, Japón, Corea del Sur y Taiwán impulsaron reformas agrarias en el siglo XX que facilitaron sus procesos de industrialización. Contrario a esto, en los países latinoamericanos ha sido muy difícil hacer lo propio para cambiar la estructura agraria heredada de la colonia (Kalmanovitz, 2011), lo cual es un impedimento para los procesos de industrialización, dado que ningún desarrollo industrial es factible sin el apoyo a una "revolución agrícola" que sea fuente de acumulación y desarrollo (Barre, 1968). Esto es ratificado por Rostow (1959), quien destaca la importancia de la productividad agrícola como "precondición" para lograr "la industrialización sostenida" y evitar la "estrangulación" del proceso de modernización 19 (5). El aumento de la productividad en el campo es necesario, toda vez que éste es el sector abastecedor de materias primas del sector secundario, la producción de algodón es un ejemplo clásico. Pero también la importancia del desarrollo del sector agrícola radica en que éste, a su vez, es fuente de demanda de bienes industriales y por tanto es menester para el desarrollo industrial el incremento de la productividad agrícola y de la renta que permita ampliar el mercado interno (Tirado, 2010). En este orden de ideas, desde la intuición de los teóricos del desarrollo, la productividad en el campo no es solo necesaria para crear ahorro y demanda interna de bienes industriales, sino también para liberar trabajo y permitir que una menor mano de obra alimente a una creciente población urbana, donde

\footnotetext{
${ }^{19}$ Rostow (1959) habla también de la necesidad de una transformación política como precondición para el despegue económico de un país.
} 
se asientan las factorías (Ortiz y Uribe, 2012). De ahí la importancia de las reformas en el campo que busquen su modernización y su productividad.

Continuando con el caso de Japón, además de poner en orden el sector agrícola la estrategia de éste país, y en menor medida de los Tigres Asiáticos, fue la de buscar aumentos de productividad en las actividades transables más complejas y en el caso de China e India, buscaron el incremento de la competitividad de su canasta exportable a través de los bajos salarios relativos, superando así a los países del centro y rechazando la idea del mercado competitivo y empleando políticas selectivas que impulsaron actividades "industriales transables" que elevaron tanto las tasas de crecimiento de la productividad como "del producto de la inversión y los bienes transable en el PIB" (Sarmiento, 2011: 174). En este sentido, la historia de la economía alemana también hace parte de los casos de priorización industrial (Freeman, 1995; Ortiz y Uribe, 2012).

No hay que olvidar, señala Sarmiento (2002), que las mayores tasas de crecimiento económico que han tenido Europa y EEUU han sido producto del proteccionismo y "la ampliación de la industria con relación a la agricultura" (176), proceso que evolucionó posteriormente hacia un mayor protagonismo de los servicios en la vida nacional de Estado Unidos y, en menor medida, de Europa (Sarmiento, 2014). En el caso de China y Taiwan, la participación de la industria manufacturera en el PIB fue del $40 \%$ y $36 \%$ en 1980 respectivamente, y hasta el año 2005 , permanece dicha participación alta y estable en muchos países del Asia (Naudé y Szirmai, 2012).

Existen distintas explicaciones al desarrollo industrial, por ejemplo, Acemoglu y Robinson (2012) pone gran énfasis, desde una óptica liberal, en las instituciones que se configuran tanto en la esfera política como económica, las cuales pueden acelerar o retrasar el desarrollo económico según su naturaleza extractiva o inclusiva, son entonces las instituciones que adoptan los países las que explican la riqueza y pobreza de los países. Chang (2007), por su parte, le otorga gran importancia a las políticas industriales de los gobiernos y al grado de intervención del Estado en el proceso de acumulación de capital. Un hecho interesante que se ha reseñado hasta el momento en este artículo es el de la intervención estatal como condición necesaria para el establecimiento de las primeras actividades industriales y su posterior desarrollo. Si bien el grado de intervención ha variado de país en país a lo largo de la historia, no se ha hallado en la literatura consultada un caso en el cual el desarrollo industrial manufacturero se diera de forma silvestre sin intervención de políticas industriales, de hecho, las inversiones estatales de alto riesgo en la investigación básica ${ }^{20}$ y posterior desarrollo tecnológico explica el alto grado de innovación de los países hoy día del centro y demuestra que la participación estatal en la economía va más allá de la simple regulación y corrección de los fallos del mercado (Mazzucato, 2011). Un caso interesante es el de Colombia, gracias a la intervención del Estado mediante políticas sectoriales el país logró cierto desarrollo manufacturero (Ortiz y Uribe, 2012), el cual se vio interrumpido por una serie de factores que no es menester del presente artículo indagar en ellos. Lo expuesto hasta el momento controvierte la visión hegemónica que demoniza al Estado y lo cataloga como factor que impide el crecimiento económico.

\section{Características de los países pe- riféricos}

En los primeros años del desarrollo del ser humano hasta principios del siglo XVIII, hubo ausencia de cambios progresivos violentos que dieran origen a un crecimiento material exponencial, lo cual se atribuye "a la notable ausencia de mejoras técnicas importantes y al fracaso en acumular capital" (Dobb, 1982: 86, citando el trabajo de Keynes La Economía de Nuestros Nietos). De igual forma, los países de la periferia al encontrarse en los primeros estadios del desarrollo económico comparten esta ausencia de progreso técnico ${ }^{21}$. Su economía se caracteriza por su mayor participación en el sector primario y por tener una mala distribución de la tierra; grandes latifundios junto a pequeñas parcelas de tierra con escaso capital y de muy baja productividad sin excedentes en su producción (economía de subsistencia). Existe una alta densidad de la población con relación al área de tierra cultivada, y por tanto, desempleo, lo cual también se refleja en la emigración del campo a la ciudad y de tal manera incrementa el desempleo y el subempleo, con el agravante de la mala alimentación ${ }^{22}$ y la alta inci-

\footnotetext{
20 "la inversión en investigación básica es un ejemplo típico de ?falla del mercado? donde el mercado sólo no produciría suficiente investigación básica y por lo tanto el gobierno debe participar" (Mazzucato, 2011: 51) (traducción del inglés al español realizada por el autor).

${ }^{21} \mathrm{~A}$ partir de la mitad del siglo XIX el mundo se dividió entre países industrializados y países agrícolas, países del trópico permanecieron predominantemente agrarios o mineros, mientras que los países occidentales y los países de la industrialización tardía en el Asia, como el Japón, se industrializaron. El crecimiento industrial en los países del centro crearon crecientes demandas de bienes primarios, los avances tecnológicos en las comunicaciones crearon las condiciones para un creciente comercio, de esta manera se creó la división internacional del trabajo (Naudé y Sziemai, 2012).

${ }^{22}$ Como bien se conoce en la teoría del desarrollo, la alimentación es indispensable para el aumento de la capacidad productiva y por lo tanto, para mejoras en el crecimiento económico (Ray, 1998, ver curva de capacidad).
} 
dencia de enfermedades y consecuente reducción de la eficiencia y la capacidad productiva del individuo (Dobb, 1982).

En países de baja renta se tiene una especie de estado estacionario ${ }^{23}$ caracterizado por la baja tasa de ahorro, producto a su vez de la baja renta real, por tanto baja formación de capital y reducida oferta del mismo para la inversión, a la par, una insuficiente demanda de capital por el bajo estímulo a invertir, lo que se explica por la persistente escasez de mano de obra calificada indispensable para el empleo de técnicas modernas. Además, no se cuenta con infraestructura (puertos, vías de comunicación, sistema bancario) y el gasto de consumo interior es bajo - por la baja renta real -dada la estreches del mercado que está en función del nivel de productividad y del volumen de la producción. De manera que el nivel de producción de una sola industria incipiente no puede crear su propia demanda, en virtud de la enorme gama de necesidades de los agentes económicos (Barre, 1968). Se puede aseverar entonces que la economía se encuentra en una situación de trampa de pobreza en la que no se generan las condiciones para emprender el crecimiento económico sostenido (Ortiz y Uribe, 2012). En este caso, tampoco se cumpliría la ley de Say, como se vio anteriormente.

En el mismo sentido, Dobb (1982) mantiene que la insuficiencia en la demanda impacta negativamente a la oferta, el bajo consumo no estimula inversiones en la industria, de tal suerte, el capital privado encuentra su rentabilidad en el comercio interno o externo (exportando e importando bienes de lujo) o en la compra de tierra para la especulación y "construcción de edificios de lujo" (Dobb, 1982: 97)

Esta situación de insuficiencia de demanda induce a la concentración de la inversión extranjera directa en actividades económicas de exportación y no en las actividades productoras de artículos para el mercado interno, toda vez que "los capitales privados tienden siempre a desplazarse hacia los países en que existe un mercado amplio y próspero" (Barre, 1968: 44). Junto a los problemas derivados de una demanda interna insuficiente, se tiene que los países de la periferia se caracterizan por tener una reducida diversificación en la canasta exportable, "su comercio exterior está basado en uno o dos productos... Esto significa que estos países son muy vulnerables a las fluctuaciones del mercado en el caso de un producto principal" (Dobb, 1982: 100). En consecuencia, a estos países les queda difícil provi-

\footnotetext{
${ }^{23} \mathrm{El}$ estado estacionario en los modelos neoclásicos es una ?situación en la que el ingreso per cápita no varía -el producto crece al ritmo de crecimiento de la población? (Ortiz y Uribe, 2012: 72).
}

sionarse de bienes de capital a través de la importación debido a los problemas en la cuenta corriente que se deriva de la inestabilidad de los precios de su producto estrella de exportación. En este sentido, la falta de "equipo de capital" es la causa del desempleo y el subempleo en la periferia (Perez, 2011).

Esta escasez de factores productivos se reflejan en la baja productividad agrícola, a pesar de que sigue siendo el sector predominante; coexiste la emigración de elementos de la población económicamente activa dotada de capital humano junto a la emigración de capital, con el agravante de la captura del ahorro de estos países periféricos para reorientarlo hacia países en desarrollo. La baja acumulación de capital humano funciona como cuello de botella a la inversión en formación de capital fijo para ampliaciones de la producción. Si bien existe una sobre oferta de trabajo en términos cuantitativos, se tiene escasez en términos cualitativos, dado que no se ha formado la cantidad de capital humano necesario para el funcionamiento de los proyectos de inversión (Barre, 1968).

Estas características endógenas de demanda y oferta coexisten con otras de orden exógeno, concerniente al capital foráneo y su lógica de acumulación. Las dinámicas capitalistas de acumulación pueden impedir el desarrollo de las fuerzas productivas de los países de baja renta relativa, es así como se ha visto que históricamente los beneficios obtenidos por el capital no fueron reinvertidos en los lugares donde ocurría el proceso productivo, sino que fueron despachados hacia aquellos países de donde provino el capital, como tampoco los beneficios se dirigieron a la "inversión industrial en gran escala, que sabemos por experiencia es el verdadero factor dinámico del desarrollo económico moderno; es esta la razón principal por la que los países subdesarrollados no pudieron seguir la vía capitalista del desarrollo económico"; el ahorro privado de los países periféricos en lugar de ser invertido en ramas de la producción cuyo impacto en el desarrollo es mayor, se ha dirigido históricamente hacia la inversión en actividades que buscan proveer de materias primas a las fábricas y de alimentos a la fuerza laboral de los países del centro, en este orden de ideas, la economía periférica se "convirtió en unilateral"; tanto las actividades extractivas de recursos naturales como las actividades de producción de artículos alimenticios han sido las receptoras por excelencia del capital que busca específicamente la exportación de estos bienes (Economic Development, Planning and International Cooperation, citado por Dobb, 1982: 96-97)

Paul Baran (como se cita en Dobb, 1982), encuentra que el poco excedente de la periferia se emplea de forma inadecuada siendo "absorbido por 
diversas formas de consumo excesivo de las clases altas, por un aumento de los atesoramientos tanto en el interior como en el exterior, por el mantenimiento de enormes burocracias improductivas y aparatos militares no menos redundantes y costosos" (119). El ahorro de la periferia no se dedica a la inversión productiva sino al depósito en países del centro, se atesora mediante la compra de metales preciosos o se dirige a la construcción de residencias lujosas, a la compra de tierras o inmuebles para la especulación (Barre, 1968, Dobb, 1982).

En consecuencia a lo hasta aquí reseñado, no hay capitalización en estas economías; se tiene un alto gasto en consumo y bajo gasto en inversión productiva. Lo anterior se puede esquematizar con el planteamiento algebraico de Keynes (2014), a saber, $Y=C+I$. Donde el producto $\mathrm{Y}$ se distribuye en consumo $\mathrm{C}$ y en inversión $\mathrm{I}$, siendo éste último la base de la acumulación de capital al referirse al "aumento en el equipo productor" (98). Siguiendo este razonamiento, lo que se destina al consumo no se puede destinar a la inversión. Los países periféricos dedican la mayor porción de su producto al consumo e imposibilitan así la acumulación de capital mediante la inversión productiva. Sin embargo, Dobb (1982) mantiene que si se tiene en cuenta "la fuerza vertiginosa del crecimiento compuesto a altas tasas" (121) se puede tener la esperanza de que los países periféricos puedan salir del atraso ampliando su inversión y su consumo una vez hayan logrado una tasa de crecimiento adecuada y se reinviertan los incrementos, entonces se tendrá un margen para ser destinado tanto a la inversión como al consumo; la población no tendría entonces que hacer grandes sacrificios en el consumo para invertir, de ahí la importancia de los aumentos de la productividad. El autor propone la intervención del Estado mediante la planificación para mantener la tasa de crecimiento "a un nivel adecuado durante una década o dos", específicamente duran los primeros años del despegue económico (122).

En consecuencia, un país que quiere crecer y por tanto requiere elevar sus tasas de ahorro (como lo señala el modelo Harrod-Domar), deberá buscar la forma de direccionar el ahorro de las clases de alto ingreso, "de los empleos menos útiles hacia los empleos más útiles y... obligarlas a reducir su consumo" (Informe de las Naciones Unidas 1949, citado en Barre, 1968: 45), de lo contrario, no se podrá acumular y conducir tal capital hacia la producción compleja, toda vez que los estímulos del mercado no direccionarían la inversión hacia actividades industriales de mayor complejidad ni se avanzaría por la escalera tecnológica, lo cual impediría el desarrollo económico dado que los bienes de mayor sofisticación e intensivos en tecnología presentan una demanda infinita al abrirse la economía al mercado mundial (Sarmiento, 2002, 2011), contrario pasa con los bienes intensivos en trabajo -factor abundante de la periferia -los cuales al ser sobreofrecidos no encuentran realización en el mercado (Sarmiento, 2002).

Concerniente a lo anterior, una de las políticas de las multinacionales es la de mantener en las casas matrices, localizadas en el país de origen del capital, la parte de la producción de bienes intermedios más compleja y de mayor valor agregado y componente tecnológico (Sarmiento, 2002) en donde la contribución de la producción acumulada a la productividad es mayor por las dinámicas del aprendizaje en el oficio que desencadena (Sarmiento, 2011), de tal suerte que los países en desarrollo se han visto forzados a estimular el advenimiento de las multinacionales con sus actividades complejas por medio de menores tarifas a los bienes intermedios y a las materias primas, dejando un mayor gravamen a los bienes finales y en tal virtud, se crean incentivos a la importación de estos bienes, con lo que eso implica; sustitución de empleo directo nacional (Sarmiento, 2002) y el rompimiento de los eslabonamientos productivos. Las empresas en los países periféricos tienen una alta preferencia a sustituir trabajo por la importación de bienes de capital que aumentan su productividad, y por tanto, el sistema funciona con alta productividad, pero con insuficiencia de demanda; sus economías son receptoras de grandes flujos de capital y su moneda se revalúa, por tanto se conforman estructuras productivas basadas en importaciones que generan poco empleo. Contrario a esto, los países que cuentan con estructuras productivas más complejas y con la capacidad de competir en el mercado internacional y sustituir importaciones, pueden crear más empleos formales. (Sarmiento, 2011).

Un elemento importante a tener en cuenta es que con la desaparición de empleos desaparece el aprendizaje, el cual es producto, en gran parte, de la experiencia y solo toma lugar durante la actividad (Arrow, 1962), en este sentido, el aprendizaje en la práctica es un factor importante a tener en cuenta; de no existir o desaparecer la producción en actividades complejas este aprendizaje quedaría limitado, y así mismo, los incrementos de la productividad en la economía, toda vez que si bien es cierto que la educación formal, que puede proveerse relativamente fácil mediante centros educativos, es necesaria y permite la movilidad social ascendente, es el aprendizaje en la práctica, el cual solo se adquiere si existe la actividad y se genera el conocimiento tácito $^{24}$, el que tiene impactos mayores en la productividad (Sarmiento, 2011). No en vano los

\footnotetext{
${ }^{24}$ Para indagar más sobre el conocimiento tácito y su importancia ver Ancori et al. (2000).
} 
Tigres Asiáticos dieron gran prioridad a la educación ${ }^{25}$ y a su aparato industrial de transformación (Naudé y Szirmai, 2012; Sarmiento, 2011; Chang, 2007).

En este orden de ideas, hay una fuerte necesidad en los países de alta renta relativa por el crecimiento de su componente técnico-científico dado que su población tiende a crecer a tasas pequeñas. Este fenómeno es de cierta manera explicado por Dobb (1982), quien escribe que "si la población aumenta despacio, también el ejército laboral crecerá lentamente y el capital, a medida que se acumula, tendrá necesidad de dirigirse hacia técnicas productivas más mecanizadas y ahorradoras de trabajo, incrementando la fuerza mecánica por trabajador" (89). De cierta forma se entiende, a partir de estas condiciones de escasez del factor trabajo, por qué el cambio técnico ha sido históricamente $-\mathrm{O}$ por lo menos lo fue en el siglo XIX- ahorrador de trabajo (Naudé y Szirmai, 2012: 6). Teóricamente el PIB per cápita debe incrementar en estos países del centro vía cambio técnico, y es éste último el factor relevante y medular que condiciona el crecimiento económico; en los países del centro el stock de capital aumenta a una tasa mayor al incremento de la población operando los rendimientos marginales decrecientes del factor capital que retrasan su acumulación, lo cual solo se puede solucionar con el progreso técnico (Meier y Baldwin, 1964).

Mientras que los países del centro se mantienen como países líderes elevando la productividad, los países periféricos - "en desarrollo" - crecen "copiando la tecnología y ofreciendo bajos salarios" (Sarmiento, 2002: 182), como también incorporando más capital, asimilando los inventos foráneos, progresan del aprendizaje en el oficio, de allí la importancia de atraer actividades complejas y su política de reducción tarifaria, "en este contexto, tienen un amplio margen para avanzar en la industrialización y de esta manera empujar todo el sistema económico" (Sarmiento, 2011: 144).

Los países de la industrialización tardía enseñan el camino del desarrollo a los países periféricos. Según lo expone Gerschenkron (como se cita en Naudé y Szirmai, 2012), bajo el concepto de advantages of backwardness, los países de la industrialización tardía se beneficiaron de la disposición de bienes de alto contenido tecnológico en los países del centro, por tanto, a través de la importación de

\footnotetext{
${ }^{25}$ Ortiz (2016) citando el trabajo de Levine y Renelt, quienes en un horizonte temporal (1960-1988) encuentran para un conjunto de países una robusta correlación entre la tasa inicial de escolaridad secundaria y el crecimiento del producto per cápita, afirma lo siguiente: "La correlación entre la tasa de escolaridad y el crecimiento puede indicar la importancia del nivel de acumulación de capital humano en el desarrollo económico" (31)
}

maquinaria, equipo e insumos en general, no se incurren en costes de investigación y desarrollo $(\mathrm{I}+\mathrm{D})$ que se encuentran incorporados en las importaciones, de tal suerte los países "pueden aprender acerca del estado del arte del conocimiento y tecnología internacional a través de la copia, imitación y la ingeniería inversa y la interacción científica, profesional y tecnológica" 26 (6). Con políticas sectoriales de asistencia técnica (importación de capital humano) e importación tecnológica los gobiernos pueden impulsar el desarrollo económico tal cual como sucedió en la industria del hierro en Rusia (Pounds y Montal, 1968).

Con respecto a lo señalado, el caso de China es ilustrativo. Según Sarmiento (2011) el crecimiento de países como China, que no hace mucho pertenecían a la periferia, es de tipo extensivo, incorporando mayores cantidades de factores productivos (trabajo y capital) -priorizando el sector industrial -que al cambio técnico, esto explica en gran parte las tasas de crecimiento de la Productividad Total de los Factores en las últimas cuatro décadas, que crecieron tres veces más en China que en EEUU y Europa (en donde el crecimiento es intensivo) a pesar que en estos dos últimos "la tecnología y su conversión en usos" tuviese mayor dinámica; la expansión de las exportaciones que ayudaron al crecimiento de Asia significaron importaciones que redujeron a $2 / 3$ el crecimiento de la productividad de EEUU $(178)^{27}$.

Los asiáticos han fundamentado su estrategia de crecimiento en la oferta industrial, mientras que EEUU lo ha hecho en la oferta de servicios, por tanto, los primeros han presentado tasas de crecimiento mayores a las del segundo en los últimos años (Sarmiento, 2011). En el caso de Latinoamérica, en la primera mitad del siglo XX se buscó el desarrollo industrial, éste se encontró con fuertes restricciones cómo la tradicional mala distribución del ingreso y capacidad de planta ociosa. Hoy día se suma como factor negativo el proceso de financiarización parasitario caracterizado en parte por la creciente rentabilidad del sector financiero sobre el sector productivo de la economía (Salama, 2005). Son estas condiciones las que explican la necesidad de la intervención del Estado a través de la política industrial, lo cual se examinará a continuación.

\footnotetext{
${ }^{26}$ Traducción del inglés por el autor.

${ }^{27}$ En EEUU y Europa se tiene una economía en donde se ha elevado la productividad del trabajo y del capital a través de la competencia y la automatización, mientras que en Asia se ha dispuesto del aumento de las horas laboradas y la ampliación de equipo y maquinaria, acompañado de instituciones (reglas de juego) que restringe la sustitución de trabajo por tecnología, en otras palabras (Sarmiento, 2011).
} 


\section{Estado e industrialización: la política industral}

Desde los planteamientos neoclásicos de competencia perfecta, el libre funcionamiento de los mercados da como resultado la eficiencia en el intercambio y en la producción, y por tanto, la intervención del Estado, dada las preferencias de los agentes económicos, reduce la eficiencia que hubiese resultado de la libertad de los mercados (Jiménez, 2011). Como lo expone Mazzucato (2011) los economistas neoclásicos mantienen la idea de que el gasto público financiado con deuda o impuestos ${ }^{28}$, conlleva al encarecimiento del crédito, lo que ralentiza la inversión (efecto expulsión), y a la disminución del rendimiento privado del capital, lo que es negativo para el crecimiento económico. Desde esta perspectiva, el gasto público "desalentaría a la inversión privada, el capital extranjero marcharía al exterior y conduciría a medidas «no económicas» y al derroche, para no mencionar que favorecería «pensamientos peligrosos» de planificación económica." (Dobb, 1982: 113).

Sin embargo, se conoce que factores dinamizadores del crecimiento, como son la innovación, no se producen de forma espontánea sino que están en función del medio ambiente económico (Meier y Baldwin, 1964). A lo largo de la historia el Estado ha jugado un papel medular en el desarrollo económico de los países del centro al emplear las políticas públicas industriales (Chang, 2007) y esto deja en firme que el papel de los gobiernos va más allá de la corrección de las fallas del mercado y en cambio, debe intervenir para garantizar la infraestructura que cree los mercados y les permita funcionar correctamente (Mazzucato, 2011, Ortiz y Uribe, 2012), incluso, se puede afirmar la imposibilidad de un desarrollo partiendo de condiciones iniciales desfavorables sin el accionar de un Estado que cree o permita crear las condiciones necesarias para la acumulación ${ }^{29}$ (Barre, 1968; Dobb, 1982, Chang, 2007; Sarmiento, 2002, 2011; Naudé y Szirmai, 2012; Ortiz y Uribe, 2012.). La historia del capitalismo en los países del centro ha sido la historia del proteccionismo y el fomento a la actividad productiva (Chang, 2003).

\footnotetext{
${ }^{28}$ Según la idea neoclásica los impuestos y el crecimiento económico se correlacionan de forma negativa, sin embargo, Stiglitz (2014) expone el caso de Suecia, país que tiene unos elevados impuestos y que durante el periodo 2000-2010 creció mucho más deprisa que EEUU. Por tanto, los impuestos no necesariamente implican menor crecimiento económico, por el contrario, pagan el gasto en inversión que no realiza el sector privado (69).

${ }^{29}$ La intervención del Estado a través de políticas públicas de diversa índole se justifica en situaciones de trampa de pobreza, cuando la población es tan pobre que no puede llevar a cabo procesos de acumulación (Ortiz y Uribe, 2012).
}

En la totalidad de los países occidentales el Estado ha jugado el rol cardinal como constructor de infraestructura para ampliar los mercados y permitir la acumulación de capital (Barre, 1968) y como promotor del cambio técnico (Mazzucato, 2013, Naudé y Szirmai, 2012). Incluso, en América Latina el papel del Estado fue crucial para el crecimiento industrial (Ocampo, 2008). Barre (1968) expone el caso concreto de Inglaterra y Francia. En el primero el Estado intervino para favorecer la marina mercante y los cambios internacionales. A pesar de que el desarrollo industrial estaría en manos de la iniciativa privada el desarrollo industrial no ocurrió bajo los dictámenes del libre mercado (Naudé y Szirmai, 2012). En el caso de Francia, el Estado constituyó el único cliente de las manufacturas, favoreciendo con subvenciones a los mercaderes que quisieron fundar empresas, además de incentivar a la nobleza y al clero a otorgar crédito, mientras que por otro lado, desarrolló la enseñanza técnica ${ }^{30}$ (Barre, 1968). El autor también pone gran énfasis en el desarrollo nipón, caracterizado por que el Estado realiza subvenciones a las empresas privadas, asimismo que crea bancos para el sector primario y secundario de la economía, "desarrolla los astilleros de construcción naval", además de obras de infraestructura; "A partir de 1880, el Estado favorecerá, sin embargo, el desarrollo "privado" de la economía, que su acción precedente había preparado" (65). Como lo mencionara Sarmiento (2014), el desarrollo tanto de la industria como de la agricultura en una economía depende de la acción del Estado para garantizarles que el incremento de su productividad se alinea con la demanda. En el mismo sentido, las exportaciones de los países no son el resultado de un proceso silvestre o automático, es el resultado de las condiciones creadas por la política industrial de los países (Naudé y Szirmai, 2012; Chang, 2003, 2007; Sarmiento, 2002, 2014).

En el caso de Estados Unidos, el Estado jugó un papel crucial al implementar políticas públicas de educación que buscaron profundizar "la educación práctica" y los conocimientos de ingeniería y ciencia. La ley Morril (1862) fue un ejemplo de fomento a la "instrucción ingenieril mediante la donación de terrenos públicos a cada Estado para que costease una o varias escuelas" (Aparicio, 2013: 65).

La experiencia del Este Asiático también atestigua la importancia de la participación activa del Estado; se hicieron intervenciones en el tipo de cambio, en el sector financiero para elevar el ahorro y conducirlo a la inversión, y se crearon políticas industriales, agrícolas y comerciales selectivas con-

\footnotetext{
30 "En Francia, por el contrario - al caso inglés - es el Estado el que financia las empresas industriales: de 1740 a 1780, el gobierno les da o les presta 6800000 libras" (Barre, 1968: 69)
} 
ducentes al aumento de la productividad mientras se redujeron los salarios para impulsar las exportaciones y sustituir importaciones; gracias a estas políticas se ha logrado tener grandes productividades en los sectores transables y bajas en los servicios; con crecimientos del producto cercanos al $10 \%$ y de la renta per-cápita del $8 \%$ (Sarmiento, 2011). China, Japón y Corea del Sur se desarrollaron gracias a un proceso de industrialización caracterizado por la fuerte intervención del Estado, formación de capital humano, innovación y el conocimiento (Valencia, 2016). Por el contrario, los países que han abandonado su política industrial y los instrumentos de intervención en la política comercial, y le han apostado al modelo de libre mercado, han sufrido un debilitamiento tanto industrial como agrícola y por tanto de su productividad total. (Sarmiento, 2014: 413).

Cuando se inicia una nueva actividad en la economía, la productividad es baja debido a la baja acumulación del conocimiento sobre la misma, posteriormente conforme incrementa la producción acumulada incrementa el aprendizaje en el oficio y éste a su vez impulsa incrementos en la productividad, la cual tiene rendimientos decrecientes hasta llegar a cero, punto en el cual no hay cabida al aprendizaje, este disminuye con la producción acumulada. Por tanto, de lo anterior hay que entender que las nuevas técnicas de producción y las nuevas actividades económicas van a estar caracterizadas en sus inicios por una baja productividad; "la participación en actividades complejas requiere mucho tiempo para manifestarse en la productividad" (Sarmiento, 2011: 208). Una muestra de esto se encuentra en la historia; en los primeros años de la invención del barco a valor en 1807, la navegación a vapor era más lenta y costosa que la realizada en barcos de vela y por tanto, muchos comerciantes y empresarios eran reacios a su empleo, pero "no tardaron en darse cuenta sobre sus ventajas en el futuro próximo" (Mijailov, 2016). Esto enmarca la naturaleza dinámica del aprendizaje y la mejora a través de la producción acumulada de los nuevos bienes (Sarmiento, 2011; Ortiz y Uribe, 2012).

Los primeros países en industrializarse llevan la delantera en términos de aprendizaje y productividad, de tal suerte que la periferia no podría competir dentro de actividades complejas en condiciones de libre mercado. En consecuencia, se debe asegurar el mercado interno a la industria nacional con políticas comerciales fundamentadas básicamente en aranceles; la intervención del Estado es necesaria para corregir los incentivos generados por el mercado que inducen al aparato productivo hacia actividades menos complejas; en la periferia los incentivos del mercado no le dan prioridad a la industria, sino a actividades tradicionales intensivas en recur- sos naturales que cuentan con mayor productividad relativa o ventaja comparativa, pero de baja complejidad. En este orden de ideas, el mercado impide el funcionamiento de una economía que emplee de forma intensiva el conocimiento, de manera que las ganancias del comercio internacional son menores a las resultantes de la acumulación del aprendizaje y la producción que se dan bajo un marco proteccionista (Sarmiento, 2002; 2011; 2014). En todo caso, la protección a la industria incipiente debe ser temporal, "porque la acumulación de producción reduce la diferencia de productividad" (Sarmiento, 2014: 161).

La idea de la protección a la industria queda también expresada en Chang (2003) al hablar de la "industria infantil", lo cual hace referencia a las actividades industriales incipientes donde el aprendizaje se inicia y por tanto la competitividad es baja. Para el autor, dichas actividades industriales sería excluidas por la competencia en el libre mercado, lo que se puede evitar con políticas públicas que la protejan hasta que alcance la maduración o mayor competitividad; por ejemplo, las políticas de la industria infantil aplicadas por Gran Bretaña y Estados Unidos se constituyeron básicamente de aranceles a las importaciones, o en algunos casos, prohibición de importaciones, y bajos aranceles a las materias primas;

"Si bien la protección de las industrias infantiles a través de tarifas no pueden garantizar el éxito económico, el éxito sin éstas parece ser la excepción y no la regla. Hay un patrón histórico notablemente persistente, que se extiende desde la Gran Bretaña del siglo XVIII hasta la Corea del final del siglo XX, donde el éxito del desarrollo económico fue alcanzado con la ayuda de medidas de protección a la industria infantil" ${ }^{a}$

(Chang, 2003:48)

${ }^{a}$ Traducción del inglés realizada por el autor.

Como ya se ha hecho mención en lo reseñado anteriormente, los países periféricos adolecen de falta de capital, pero poseen el factor trabajo en abundancia. La teoría neoclásica ha sostenido que la política económica, de existir, debe ir encaminada a desarrollar aquellas ramas de la producción intensivas en trabajo en virtud de su alta disponibilidad relativa y por tanto, los fondos de inversión deben ser direccionados a las actividades que maximicen su rendimiento en términos de empleo del factor trabajo y crecimiento económico, en otras palabras, se debería apuntar a industrias intensivas en mano de obra en lugar de capital (industrias de baja relación capital/trabajo). En consecuencia, se propende por la estrategia de desarrollo basada en 
el coste mínimo; se debe evitar hacer inversiones en maquinaria costosa y de la más elevada tecnología y en su lugar, dotar al trabajo de los equipos más baratos, toda vez que es posible emplear "más herramientas y de esta forma conseguir un aumento del empleo superior a cualquier otra política de desarrollo, y así incrementar la renta nacional" (Dobb, 1982: 124).

Basado en lo anterior, uno de los principales modelos de comercio internacional, el modelo Heckscher-Ohlin, a través de la formalización algebraica concluye que el patrón de comercio de las economías está definido por la abundancia relativa del factor con los que cuentan (Krugman et al., 2012). En éste orden de ideas, los países periféricos deben priorizar las industrias artesanales (cottage industries) en lugar de las industrias conformadas por factorías equipadas con bienes de capital modernos, centrar entonces la política económica en la industria ligera o liviana en lugar de la pesada, aumentando la oferta de bienes de consumo para el mercado interno o externo (Dobb, 1982). Esta estrategia se enmarca en la industrialización tradicional (Dobb, 1982) o industrialización espontanea (Muns, 1972).

Landes (como se cita en Ortiz y Uribe, 2012) reflexiona sobre lo concerniente a la alternativa económica del coste mínimo; al igual que Sarmiento (2011), afirma que la teoría de las ventajas comparativas se basa en condiciones del presente y por tanto tiene una visión estática de la realidad, mientras que el proceso de desarrollo económico de los países es dinámico, cambiante ${ }^{31}$ y se "construye sobre la base de la abstinencia de hoy para la abundancia del mañana" (Landes, como se cita en Ortiz y Uribe, 2012: 30). En la misma dirección, Dobb (1982) aclara que un "curso de acción" que maximiza el empleo y la producción en un momento dado, no es el mismo "curso de acción" que maximizaría el crecimiento potencial de la economía, y son las políticas que buscan el crecimiento potencial de la economía las que, aunque teniendo tasa de crecimiento y empleo inferiores en el corto plazo, capacitan el crecimiento más rápido de la producción, el empleo y consigo el consumo, superando los niveles en un momento dado de los alcanzados por otra política de corto plazo.

Dado que se conocen los determinantes del desarrollo y la estructura industrial, el Estado puede escoger a los ganadores ${ }^{32}$ remitiéndose a las activi-

\footnotetext{
31 "Hace 20 años nadie podía imaginar que los chinos pudieran producir algo diferente de bicicletas y hoy en día su productividad total de los factores crece cuatro veces más que la de los países desarrollados" (Sarmiento, 2014: 158).

32 Mazzucato y Perez (2014) cree conveniente la creación de un marco teórico que le permita a los estados no solo socializar los riegos de las inversiones sino también las ga-
}

dades industriales menos complejas que no se producen y que disponen de mayor demanda. En este sentido, la protección debe ser gradual, comenzando por los bienes de mayor productividad relativa (de menor diferencial de productividad) frente a los países avanzados. Conforme aumente la productividad se retirará la protección a la producción de otros bienes más sofisticados, de tal forma el país trepa por la escalera tecnológica, pasando de producir bienes de ventaja comparativa o mayor productividad relativa a producir bienes de menor ventaja comparativa; "Al final se lograría una estructura altamente diversificada, con productos de la más diversa complejidad" (Sarmiento, 2014: 163). No obstante, se debe tener en cuenta, como bien lo afirma Adelman (2002), el proceso de desarrollo económico no es lineal y es multifactorial, éste se da dependiendo de las condiciones iniciales y las características históricas particulares de cada país.

Mazzucato $(2011,2014)$ argumenta la necesidad imperiosa de cambiar el marco usado para determinar las tareas de los gobiernos en el desarrollo económico; estos en las últimas décadas han estado relegados a la corrección de los fallos del mercado, sin embargo, sí se quiere un crecimiento sostenible, éste debe ser inteligente e inclusivo y esto se logra con políticas publicas tendientes a crear y darle forma a los mercados. En este sentido ha sido el Estado quien implementó y financió con fondos públicos las políticas públicas que dieron origen a tecnologías como la Internet, el GPS, la pantalla táctil y el sistema SIRI, además de la tecnología de uso general como la energía y las tecnologías de la comunicación (Mazzucato, 2013, 2014). La necesidad de la intervención del sector publico también radica en la naturaleza del proceso de innovación, proceso el cual puede tardar de 15 a 20 años en desarrollarse completamente (Mazzucato y Perez, 2014), lo cual no es muy atractivo para el capital privado si a lo demás se le añade el grado de incertidumbre (Mazzucato, 2013).

\section{Conclusiones}

Como corolario se puede afirmar que los procesos de desarrollo industrial están caracterizados, en primer lugar, por una movilización de la población del campo a la ciudad; en este sentido la industria manufacturera ha sido el camino para el desarrollo de las economías del centro. En segundo lugar, el proceso de desarrollo atestigua la intervención del

nancias. La autora ilustra la situación tomando el ejemplo de la financiación pública de empresas como Solyndra y Tesla Motors, la primera un fracaso en donde se compartieron las perdidas con los contribuyentes, la segunda un éxito que fue privado. 
Estado, ya sea como claramente lo dice Mijailov (2016) expropiando a la fuerza a los propietarios de la tierra sin poder político, o como lo afirman Chang (2003, 2007), Sarmiento (2011), Ortiz y Uribe (2012), creando las políticas de protección e impulso a la incipiente industria nacional.

También se concluye a partir del corpus bibliográfico revisado, que el libre mercado impide el desarrollo industrial y por tanto los países deben estar resueltos a la implementación de políticas proteccionistas, políticas comerciales y tecnológicas, que permitan el crecimiento de la industria. A través de las políticas industriales los países periféricos tienen la posibilidad de diversificar su aparato productivo y de producir toda la gama de bienes del espectro industrial subiendo por la escalera tecnológica; produciendo gradualmente bienes cada vez más complejos y de mayor demanda. Esto solo es posible dentro de un sistema de protección a la industria naciente, de lo contrario las economías hoy día de la periferia mantendrían su estructura productiva en función de la oferta de materias primas y bienes poco complejos, lo que significa el desaprovechamiento de las ventajas del aprendizaje en el oficio y del potencial de crecimiento que este implica.

Finalmente, como lo señala la literatura revisada, los países que han puesto en orden su sector agrícola y han implementado políticas industriales exigiéndole resultados a los sectores protegidos, como ha ocurrido en los casos de los países de Asia del Este -han logrado desarrollar sus economías. La historia económica de los países hoy día del centro y los planteamientos teóricos de los modelos de crecimiento endógeno, como del estructuralismo, avalan la intervención de las políticas públicas en el sector industrial para lograr que la periferia cambie su estructura productiva y logre mayores y sostenidas tasas de crecimiento económico. En este sentido, dadas las bondades de la industria para el crecimiento y el desarrollo económico los gobiernos deben tener en su agenda el abanico de políticas que impulsen el sector y procurar que dichas políticas se mantengan para su desenvolvimiento de largo plazo.

"Nada contribuye más a promover el bienestar público como la exportación de bienes manufacturados y la importación de materias primas extranjeras" (Walpole citado en Chang, 2007: 199)

\section{Referencias}

Acemoglu, D. y Robinson, J. (2012). Why Nations Fail. Crown Business, New York.
Adelman, I. (2002). Falacias de la Teoría del Desarrollo y sus Implicaciones en Política. En Meier, G. y Stiglitz, J. E., editores, Fronteras de la Economía del Desarrollo. Banco Mundial.

Ancori, B., Bureth, A., y Cohendet, P. (2000). The Economics of Knowledge: The Debate about Codification and Tacit Knowledge. Industrial and Corporate Change, pp. 255-287.

Aparicio, A. (2013). Historia Económica Mundial Siglos XVII-XIX: Revoluciones Burguesas y Procesos de Industrialización. Economía Informa.

Arrow, K. (1962). The Economic Implications of Learning by Doing. The review of economic studies, 29(3).

Barre, R. (1968). Crecimiento económico.

Chang, H. J. (2003). Kicking Away the Ladder: The Real History of Free Trade. Foreign Policy in Focus. Interhemispheric Resource Center, Silver City.

Chang, H. J. (2007). Bad Samaritants: The Myth of Free Trade and the Secret History of Capitalism. Bloomsbury Press.

Chenery, Robinson, y Syrquin (1986). Industrialization and Growth a Comparative Study. A world Bank Research Publication. Oxford University Press.

Cimoli y Porcile (2015). Productividad y cambio estructural: el estructuralismo y su diálogo con otras corrientes heterodoxas. En Neoestructuralismo y corrientes heterodoxas en América Latina y el Caribe a inicios del siglo XXI.

Dobb, M. (1948). Soviet Economic Development Since 1917. Routledge/Kegan Paul LTD, Londres.

Dobb, M. (1982). Capitalismo, crecimiento económico y subdesarrollo. OIKUS TAU.

Domar, E. (1946). Capital expansion, rate of Growth, and Employment. Econometrica, 14(2):137-147.

Freeman, C. (1995). The National System of Innovation in historical perspective. Cambridge Journal of economics, 19(1):5-24.

Harrod, R. F. (1939). An essay in dynamic theory. The economic journal, 49(193):14-33.

Hirschman, A. O. (1977). Enfoque generalizado del desarrollo por medio de enlaces, con referencia especial a los productos básicos. El trimestre económico, 44(173 (1):199-236. 
Javin, A. (1975). Esbozo de la historia de la industrialización de la URSSq. Editorial Progreso.

Jiménez, F. (2011). Crecimiento Económico. Enfoques y Modelos. Libros PUCP/PUCP Books.

Kaldor, N. (1961). Capital accumulation and economic growth. En The theory of capital, pp. 177222. Springer.

Kalmanovitz, S. (2011). Nueva historia económica de Colombia. Taurus.

Keynes, J. M. (2014). Teoría general de la ocupación, el interés y el dinero. Fondo de cultura económica.

Krugman, P. R., Obstfeld, M., y Melitz, M. J. (2012). Economía international: Teoría y política. Pearson.

Landes, D. S. (2015). Wealth and poverty of nations. Hachette UK.

Mazzucato, M. (2011). The entrepreneurial state. Soundings, 49(49):131-142.

Mazzucato, M. (2013). The entrepreneurial state: Debunking the public vs. private myth in risk and innovation. Anthem, London.

Mazzucato, M. (2014). Building the Entrepreneurial State. A new framework for envisioning and evaluating mission-oriented public investments. Mission-Oriented Finance for Innovation, 20.

Mazzucato, M. y Perez, C. (2014). Innovation as growth policy: the challenge for Europe.

Meier, G. y Baldwin, R. (1964). Desarrollo económico. Aguilar.

Mijailov, M. I. (2016). La revolución industrial. Panamericana, Bogotá.

Muns, J. (1972). Industrialización y crecimiento de los países en desarrollo. Ariel.

Naudé, W. y Szirmai, A. (2012). The importance of manufacturing in economic development: Past, present and future perspectives.

Ocampo, J. A. (2008). Hirschman, la industrialización y la teoría del desarrollo Hirschman, industrialization and development theory. Desarrollo y sociedad, (62):41-65.

Ortiz, C. (2008). Aprendizaje en la Producción de Capital, Crecimiento Acelerado y Cambio Estructural. Cuadernos de Economía, XXVII(48):115-142.
Ortiz, C. (2016). Diversificación productiva y crecimiento económico. Enfoques teóricos y análisis del desarrollo socioeconómico de. Programa Editorial, Calí.

Ortiz, C. y Uribe (2012). Crecimiento Económico, Industrialización y Empleo. Programa Editorial, Valle de Cauca.

Ortiz, C. y Vásquez (2007). Aprendizaje Manufacturero, Dependencia Tecnológica y Crecimiento Económico: El Caso Colombiano. Revista Sociedad y Economía.

Pounds, N. J. G. y Montal, J. A. (1968). Geografía del hierro y el acero. Labor.

Prebisch, R. y Cabañas, G. M. (1949). El desarrollo económico de la América Latina y algunos de sus principales problemas. El trimestre económico, 16(63):347-431.

Rosenstein-Rodan, P. N. (1943). Problems of industrialisation of eastern and south-eastern Europe. The economic journal, 53(210/211):202-211.

Rostow, W. W. (1959). The stages of economic growth. The Economic History Review, 12(1):116 .

Salama, P. (2005). Â¿Por qué América Latina no puede alcanzar un crecimiento elevado y sostenido? Revista Argentina de Economía y Ciencias Sociales, 9(14):79-102.

Sarmiento, E. (2002). El modelo propio. Grupo Editorial Norma, Editorial Escuela Colombiana de Ingeniería, Bogotá.

Sarmiento, E. (2011). Transformación productiva y equidad. Escuela Colombiana de Ingeniera Julio Garavito, Bogotá.

Sarmiento, E. (2014). Distribución del ingreso con crecimiento es posible. Escuela Colombiana de Ingeniera Julio Garavito, Bogotá.

Solow, R. M. (1956). A contribution to the theory of economic growth. The quarterly journal of economics, 70(1):65-94.

Stiglitz, J. (2014). El precio de la desigualdad. Punto de Lectura, Madrid.

Tirado, A. (2010). Introducción a la historia económica de Colombia. Panamericana, Bogotá.

Tzur, M. (1961). El desarrollo industrial en Israel. Sagitario.

Valencia, M. A. (2016). La industria. Editores Aurora, Bogotá. 